\title{
Waste Dislodging and Conveyance Testing Summary and Conclusions to Date
}

\author{
M. W. Rinker \\ O. D. Mullen ${ }^{(a)}$ \\ B. K. Hatchell
}

September 1994

Prepared for

the U.S. Department of Energy

under Contract DE-AC06-76RLO 1830

Pacific Northwest Laboratory

Richland, Washington 99352

\footnotetext{
(a) Westinghouse Hanford Company

Richland, Washington 99352
} 


\section{Summary}

This document summarizes recent work performed by the Waste Dislodging and Conveyance technology development program to provide assistance with the retrieval of wastes from the Hanford single-shell tanks (SSTs). This work is sponsored by the Underground Storage Tank-Integrated Demonstration (USTID) Office with the U.S. Department of Energy (DOE) Office of Technology Development. A baseline technology of high-pressure waterjet dislodging and pneumatic conveyance integrated as a scarifier is proposed as a means of retrieval. The history and process that led to this baseline are closely linked with overall tank waste retrieval functions and requirements as well as a step-wise technical decision logic. The tests and studies described were performed to demonstrate that at least one robust technology exists that could be effectively used with low water-addition arm-based systems. Publication and communication of the results, issues, and recommendations of past and current efforts are required so that all potential users of the technology will have a common understanding of the DOE technology development work performed to date. These results are preliminary and do not represent an optimized baseline. When tests are complete, additional risk areas may be identified or alternative technology choices may be preferred.

The Waste Dislodging and Conveyance work thus far has demonstrated that waterjet mobilization and air conveyance can mobilize and convey SST waste simulants at the target rates while operating within the space envelope and the dynamic loading constraints of deployment devices. Waste simulants have been designed to challenge the retrieval process and bound tank waste properties. It is recognized that the recommended technologies are well proven in industrial applications and are quite robust, yet lightweight and relatively benign to the retrieval environment. It has also been demonstrated that the baseline approach has versatility to continuously dislodge and convey a broad range of waste forms, from hard wastes to soft sludge wastes, through the use of rather simple in-tank components. The approach also has the major advantage of being noncontact with the waste surface under normal operation, thus minimizing loads to the deployment system and the tank environment.

Most of the work to date has been performed in laboratory-scale tests consisting of separate dislodging and conveyance tests, along with some integrated system testing. Remaining issues require full-scale, long-duration testing of integrated systems to validate system performance using a wide range of simulated wastes, to establish process sensitivity to waste properties until such time that actual physical tank waste data become known. Regardless of the technology chosen for the single-shell tank waste retrieval, a validation process similar to that presented in this document will be required. 


\section{DISCLAIMER}

This report was prepared as an account of work sponsored by an agency of the United States Government. Neither the United States Government nor any agency thereof, nor any of their employees, make any warranty, express or implied, or assumes any legal liability or responsibility for the accuracy, completeness, or usefulness of any information, apparatus, product, or process disclosed, or represents that its use would not infringe privately owned rights. Reference herein to any specific commercial product, process, or service by trade name, trademark, manufacturer, or otherwise does not necessarily constitute or imply its endorsement, recommendation, or favoring by the United States Government or any agency thereof. The views and opinions of authors expressed herein do not necessarily state or reflect those of the United States Government or any agency thereof. 


\section{DISCLAIMER}

Portions of this document may be illegible in electronic image products. Images are produced from the best available original document. 


\section{Contents}

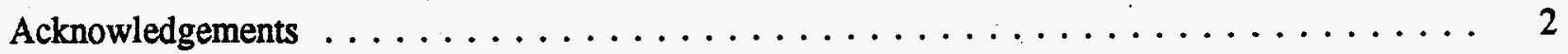

Summary $\ldots \ldots \ldots \ldots \ldots \ldots \ldots \ldots \ldots \ldots \ldots \ldots \ldots \ldots \ldots \ldots \ldots \ldots \ldots$ iii

Acronyms $\ldots \ldots \ldots \ldots \ldots \ldots \ldots \ldots \ldots \ldots \ldots \ldots \ldots \ldots \ldots \ldots \ldots \ldots \ldots \ldots \ldots$ vii

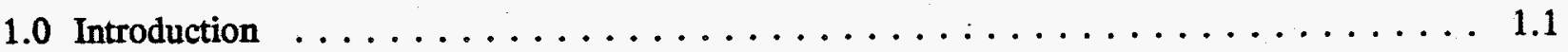

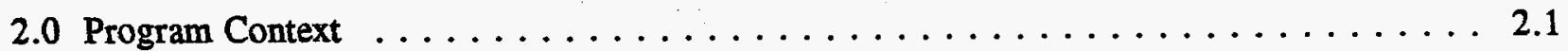

2.1 Programmatic Background $\ldots \ldots \ldots \ldots \ldots \ldots \ldots \ldots \ldots \ldots \ldots .1$

2.2 Technical Approach $\ldots \ldots \ldots \ldots \ldots \ldots \ldots \ldots \ldots \ldots \ldots \ldots \ldots \ldots \ldots \ldots$

3.0 Technology Selection $\ldots \ldots \ldots \ldots \ldots \ldots \ldots \ldots \ldots \ldots \ldots \ldots \ldots \ldots \ldots \ldots \ldots$

3.1 Early Retrieval Evaluations $\ldots \ldots \ldots \ldots \ldots \ldots \ldots \ldots \ldots \ldots \ldots .1$

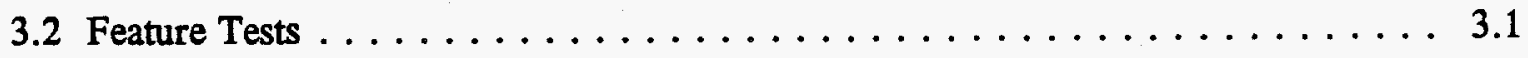

3.2.1 Dislodging Feature Tests $\ldots \ldots \ldots \ldots \ldots \ldots \ldots \ldots \ldots .1$

3.2.2 Conveyance Feature Tests $\ldots \ldots \ldots \ldots \ldots \ldots \ldots \ldots \ldots \ldots \ldots \ldots$

3.3 Technology Peer Review $\ldots \ldots \ldots \ldots \ldots \ldots \ldots \ldots \ldots \ldots \ldots .2$

3.4 Retrieval Technology Demonstration $\ldots \ldots \ldots \ldots \ldots \ldots \ldots \ldots \ldots .2$

3.5 Recent Development $\ldots \ldots \ldots \ldots \ldots \ldots \ldots \ldots \ldots \ldots \ldots \ldots .2$

4.0 System Description $\ldots \ldots \ldots \ldots \ldots \ldots \ldots \ldots \ldots \ldots \ldots \ldots \ldots \ldots \ldots \ldots \ldots \ldots$

4.1 Dislodging System $\ldots \ldots \ldots \ldots \ldots \ldots \ldots \ldots \ldots \ldots \ldots \ldots .1$

4.1.1 Functional Description $\ldots \ldots \ldots \ldots \ldots \ldots \ldots \ldots \ldots \ldots \ldots \ldots \ldots$

4.1.2 High-Pressure Waterjet Equipment Description . . . . . . . 4.1

4.2 Conveyance System $\ldots \ldots \ldots \ldots \ldots \ldots \ldots \ldots \ldots \ldots \ldots .5$

4.2.1 Functional Description ................. 4.5

4.2.2 Pneumatic Equipment Description $\ldots \ldots \ldots \ldots \ldots \ldots \ldots \ldots .5$

4.2 .3 Vacuum Blower $\ldots \ldots \ldots \ldots \ldots \ldots \ldots \ldots \ldots \ldots . . .4$

4.2.4 Air Discharge $\ldots \ldots \ldots \ldots \ldots \ldots \ldots \ldots \ldots \ldots \ldots . . \ldots \ldots \ldots \ldots$ 
4.2.5 Control System $\ldots \ldots \ldots \ldots \ldots \ldots \ldots \ldots \ldots \ldots .9$

4.3 System Integration $\ldots \ldots \ldots \ldots \ldots \ldots \ldots \ldots \ldots \ldots \ldots .9$

5.0 Technology Development Focus Areas $\ldots \ldots \ldots \ldots \ldots \ldots \ldots \ldots \ldots \ldots .1$

5.1 Waste Simulant Development for Process Qualification ........... 5.1

5.1 .1 Technical Background $\ldots \ldots \ldots \ldots \ldots \ldots \ldots \ldots \ldots \ldots \ldots \ldots \ldots \ldots$

5.1 .2 Conclusion $\ldots \ldots \ldots \ldots \ldots \ldots \ldots \ldots \ldots \ldots \ldots \ldots \ldots \ldots \ldots \ldots \ldots \ldots$

5.2 Mining Strategy $\ldots \ldots \ldots \ldots \ldots \ldots \ldots \ldots \ldots \ldots \ldots \ldots \ldots \ldots \ldots \ldots \ldots \ldots$

5.2.1 Technical Background $\ldots \ldots \ldots \ldots \ldots \ldots \ldots \ldots \ldots . .3$

5.2 .2 Conclusion $\ldots \ldots \ldots \ldots \ldots \ldots \ldots \ldots \ldots \ldots \ldots \ldots \ldots \ldots \ldots \ldots \ldots \ldots$

5.3 Maintaining a Constant Stand-Off Distance $\ldots \ldots \ldots \ldots \ldots \ldots \ldots \ldots .4$

5.3.1 Technical Background $\ldots \ldots \ldots \ldots \ldots \ldots \ldots \ldots \ldots .4$

5.3 .2 Conclusion $\ldots \ldots \ldots \ldots \ldots \ldots \ldots \ldots \ldots \ldots \ldots \ldots \ldots \ldots \ldots \ldots \ldots \ldots \ldots$

5.4 System Dynamies $\ldots \ldots \ldots \ldots \ldots \ldots \ldots \ldots \ldots \ldots \ldots .4$

5.4 .1 Technical Background $\ldots \ldots \ldots \ldots \ldots \ldots \ldots \ldots \ldots .4$

5.4 .2 Conclusion $\ldots \ldots \ldots \ldots \ldots \ldots \ldots \ldots \ldots \ldots \ldots \ldots \ldots$

5.5 Potential for Tank Wall Damage $\ldots \ldots \ldots \ldots \ldots \ldots \ldots \ldots \ldots .5$

5.5.1 Technical Background $\ldots \ldots \ldots \ldots \ldots \ldots \ldots \ldots \ldots .5$

5.5 .2 Conclusion $\ldots \ldots \ldots \ldots \ldots \ldots \ldots \ldots \ldots \ldots \ldots \ldots \ldots \ldots \ldots \ldots \ldots \ldots$

5.6 Conveyance System Capability and Integration $\ldots \ldots \ldots \ldots \ldots \ldots \ldots$

5.6 .1 Technical Background $\ldots \ldots \ldots \ldots \ldots \ldots \ldots \ldots \ldots$

5.6 .2 Conclusion $\ldots \ldots \ldots \ldots \ldots \ldots \ldots \ldots \ldots \ldots \ldots \ldots \ldots \ldots \ldots \ldots$

5.7 Testing Focus Areas $\ldots \ldots \ldots \ldots \ldots \ldots \ldots \ldots \ldots \ldots .7$

6.0 References $\ldots \ldots \ldots \ldots \ldots \ldots \ldots \ldots \ldots \ldots \ldots \ldots \ldots \ldots \ldots \ldots \ldots \ldots \ldots \ldots \ldots \ldots .1$

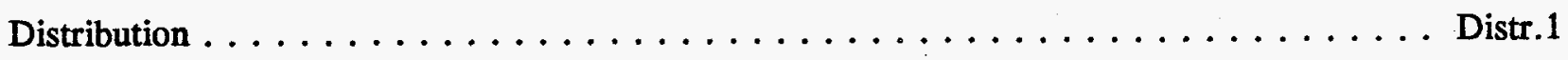




\section{Acronyms}

$\begin{array}{ll}\text { DOE } & \text { U.S. Department of Energy } \\ \text { DQO } & \text { data quality objective } \\ \text { EM } & \text { DOE Office of Environmental Restoration and Waste Management } \\ \text { EM 30 } & \text { DOE Office of Waste Operations } \\ \text { EM 50 } & \text { DOE Office of Technology Development } \\ \text { FY } & \text { fiscal year } \\ \text { HTB } & \text { Hydraulics Test Bed } \\ \text { LRM } & \text { Long-Reach Manipulator } \\ \text { MYTS } & \text { Multiyear testing strategy } \\ \text { OTD } & \text { Office of Technology Development } \\ \text { PNL } & \text { Pacific Northwest Laboratory } \\ \text { PPS } & \text { past practice sluicing } \\ \text { UHP } & \text { ultra-high-pressure } \\ \text { UMR } & \text { University of Missouri-Rolla } \\ \text { UST } & \text { underground storage tank } \\ \text { UST-ID } & \text { Underground Storage Tank - Integrated Demonstration } \\ \text { SST } & \text { single-shell tank } \\ \text { TWR } & \text { tank waste robotics } \\ \text { TWRS } & \text { tank waste remediation system } \\ \text { WD\&C } & \text { Waste Dislodging and Conveyance } \\ \text { W 340 } & \text { EM 30 Project - Tank C106 Manipulator Retrieval System } \\ \text { WHC } & \text { Westinghouse Hanford Company } \\ \end{array}$




\subsection{Introduction}

Recent work performed by the U.S. Department of Energy (DOE) Office of Technology Development Waste Dislodging and Conveyance (WD\&C) development programs has led the WD\&C to conclude that waterjet-based dislodging and air conveyance are applicable to the retrieval of the waste inside Hanford single-shell tanks (SSTs). The history and process leading to these conclusions are closely linked with overall tank waste retrieval functions and requirements as well as with a sound, step-wise technical decision logic. While waterjet dislodging and air conveyance is the baseline for the arm-based retrieval, other technologies may exist that are as applicable or more applicable to the retrieval process.

Based on the WD\&C work to date, waterjet mobilization and air conveyance have been shown to mobilize and convey SST waste simulants at the target rates while operating within the space envelope and the dynamic loading constraints of deployment devices. Waste simulants have been designed to challenge the retrieval processes at the target rates. It is recognized that the baseline technologies are well proven in industrial applications and are quite robust, yet lightweight and benign to the retrieval environment. It has also been demonstrated that the baseline approach has versatility to continuously dislodge and convey a broad range of waste forms, from hard wastes to soft sludge wastes, through the use of rather simple in-tank components. The baseline approach also has the major advantage of being noncontact with the waste surface during normal operation, thus minimizing loads to the deployment system and the tank environment.
Most of the work to date has been performed in laboratory-scale tests consisting of separate dislodging and conveyance tests, along with some integrated system testing. Remaining issues require conducting full-scale integrated testing to confirm the system's capabilities. Long-duration testing of integrated systems is needed to validate system performance over a wide range of simulated wastes, to establish process sensitivity to waste properties until such time that actual tank waste physical property data is obtained. Regardless of the technology chosen for the SST waste retrieval, a validation process similar to that presented in this document will be required.

In Section 2 of this report, the WD\&C program background and approach are summarized. Section 3 describes the technology selection process, which involved testing, peer review, and demonstration of candidate technologies. In Section 4, generic descriptions of the dislodging and conveyance systems are provided. Section 5 is a discussion of focus areas for technology development identified by the WD\&C program.

Communication of the results, issues, and recommendations of past and current efforts is required so that all potential users of the technology will have a common understanding of the DOE work performed to date. 


\subsection{Program Context}

In this section, descriptions of the WD\&C program background and technical approach provide the context for the technical discussions in succeeding sections.

\subsection{Programmatic Background}

Waste Dislodging and Conveyance activities are directed by the DOE Office of Technology Development (EM 50) Underground Storage Tank - Integrated Demonstration (UST-ID). The objective of the WD\&C effort is to develop and facilitate the transfer to industry of technology pertaining to waste retrieval from DOE's underground storage tanks. This technology will initially be available for waste retrieval from Hanford SSTs and will also be available for potential use at other DOE sites.

It is expected that hydraulic sluicing will be used to remove most of the waste in Tank C106. The remaining water, sludge, and a stubborn waste heel will be removed by waste retrieval end effectors deployed by a manipulator arm. If, for any reason, past practice sluicing techniques are not utilized (for example, if the water usage is deemed too high), there may be a need to retrieve the entire tank contents using an arm-based system.

Prior to the EM 50 UST-ID involvement in the WD\&C program, technology surveys, engineering studies, and feature tests of various potential technologies were carried out by DOE Office of Waste Operations (EM 30) engineers and laboratory researchers. The WD\&C EM 50 technology development activities are an extension of that work. Initial surveys, studies, and tests laid the foundation for the WD\&C testing program; therefore, duplication of previous efforts has been avoided. WD\&C activities have been largely coordinated through workshops and discussion with the end users to ensure a strong technical com- munication. While a close technical communication interface exists between the EM 50 technology developers and the EM 30 end users of the technology, neither organization is prescriptive or directive of the other's processes and activities.

WD\&C development and demonstration activities define efficient mechanisms for dislodging in-tank waste and hardware, set key requirements for integrated methods of transporting dislodged waste out of the tank (waste conveyance), and define efficient processes or mining strategies for removing waste. This development work has been based on the assumption that the systems will be deployed by a manipulator having a significant degree of both structural and operational flexibility. In addition, to provide a uniform basis for testing and evaluation of any candidate retrieval technologies, WD\&C has defined and prepared qualified representative waste simulants with physical properties spanning those believed to be significant to the performance of retrieval systems.

Because very little is known about the physical properties of the waste itself, a carefully constructed strategy of bounding assumptions and testing must be followed to ensure a successful retrieval effort. Industry will not have an opportunity to conduct a multiyear development program during the first-generation retrieval system acquisition, so it is essential that bounding information concerning both dislodging and conveyance be supplied by the technology developers during early phases of the firstgeneration retrieval system project.

\subsection{Technical Approach}

Over the past several years, Hanford engineers and researchers from national laboratories have conducted extensive reviews of available tech- 
nologies that might be applied to SST waste retrieval. The most promising technologies were identified, and various scoping or feature tests were performed along with engineering system studies. Early successes of the scoping and feature tests, which considered only portions of the retrieval system, pointed toward continued development.

Technical issues and concerns that drive the development include payload size envelope, waste removal rates, and dynamic loads from the dislodging and conveyance system on the deployment device. These are the primary determinants of manipulator arm configuration. It is anticipated that the design of a deployment device will be highly driven by the mobilization and conveyance technologies to be used. Early decisions on dislodging and conveyance technologies have major influence on the direction and shape of the manipulator design process.

Another key variable in the design of a longreach manipulator is the payload, the mass of the end effector, and any attached elements of the conveyance system used to retrieve the waste. Early studies estimated the size of the end effectors to be as large as a 3-ft cube and weigh as much as $1500 \mathrm{lb}$. Later estimates have reduced weights to as low as $350 \mathrm{lb}$. Given the approximate expected reach $(60 \mathrm{ft}$ vertical and $37.5 \mathrm{ft}$ horizontal) of the projected mast and manipulator, the payload determines necessary stiffness, controls requirements, and tank penetration size for the manipulator.

Regardless of the choice of retrieval technologies, an additional key challenge in the development work relates to the sparse physical property data available from tank waste core samples taken to date. These data are necessary to determine waste removal rates and methods, so some bounding assumptions must be made regarding both the test strategies and the appropriate range of waste simulants used. However, immediate Hanford retrieval needs focus on waste removal from Tank C106, which allows for some realistic bounding of waste properties for near-term testing. This and other issues revolve around the knowledge of waste simulant characteristics and the companion properties of the waste itself. Because that knowledge of the waste characteristics currently resides in the laboratories and not in industry, technology development and transfer is an element of the WD\&C program to ensure that the first arm-based deployment in a radioactive environment is successful.

Since operational requirements will strongly drive the Project W 340 design, an effective "mining" strategy must be developed for the end effector to meet operational requirements. Early WD\&C tests indicated that effective operation of end effectors in waste fields requires knowledge of the terrain and sufficient control capability to maintain appropriate stand-off distances from the surface. The probable heterogeneity of tank waste indicates that irregular surface topography and waste properties will be encountered. Blind operation could result in clogging or burying of the end effectors or lost productivity as the end effector attempts to mine previously cleared terrain. However, with a high probability of an occluded environment, simple "blind" operation may be unavoidable. There is a need for designs of end effectors that incorporate intelligent control, yet are tolerant and robust. Studies and testing of these subjects as well as many other technical challenges will determine the performance of retrieval end effectors. 


\subsection{Technology Selection}

The selection of high-pressure waterjet dislodging coupled with a pneumatic conveyance system is the culmination of several years' effort. Although many previous efforts were undertaken to address the retrieval of wastes from single-shell tanks, retrieval technology development efforts became focused with the placement of the Tri-Party Agreement in 1989 (Ecology, EPA, DOE 1989). Engineering studies were performed in early 1990 that led to feature testing in late 1990 . Peer reviews held in 1991 were followed by a 1992 technical demonstration of various successful retrieval candidates. Additional testing in 1993 and 1994 became focused on the firstgeneration retrieval system. That focus has been directed primarily at providing performance data for separate and integrated dislodging and conveyance systems in support of the first-generation system for the retrieval of Tank C106 waste.

The most complete review of previous SST waste retrieval studies appears in Gibbons et al. (1993). This engineering study identified and reviewed single-shell tank retrieval documents dating back to the 1970s. The pertinent conclusion of the review was that armbased technologies should be the reference system for single-shell tanks where net water addition to the tanks is unacceptable.

\subsection{Early Retrieval Evaluations}

Engineering studies performed in 1990 (Krieg et al. 1990) led to feature tests of technologies showing promise for retrieval. For sludge, pumping systems considered for evaluation were centrifugal pumps, positive displacement pumps, eductor pumps, and scarifiers. Other systems considered were waterjets, air jets, steam jets, carbon dioxide blast, mining equipment, contained sluicing, air conveyance, belt conveyors, screw conveyors/elevators, bucket elevators, and batch conveyers. For saltcake wastes, technologies considered were grinders, clamshell buckets, impact devices, pulverizers, scarifiers, waterjets, air conveyance, and batch conveyors. These technologies were then evaluated against a broad set of evaluation criteria. Early conclusions for dislodging and conveyance technologies included air conveyance, scarifiers, waterjets, and air jets as primary candidates. Steam jets, delumpers, pumping systems, batch conveyors, and clamshell buckets were secondary candidates.

These selections led to conducting feature tests of the primary technology candidates and some of the secondary candidates.

\subsection{Feature Tests}

The feature tests, subsequently performed in 1990, allowed Hanford engineers to gain additional insight and begin to make stronger conclusions and judgements of the various technologies. Simple feature tests were performed on a pneumatically driven needle scaler, air jets, and waterjets to determine if the technologies would be effective on either saltcake waste simulants or sludge simulants.

\subsubsection{Dislodging Feature Tests}

The tests conducted on the pneumatically driven needle scaler were qualitative (Squires 1990a). Scalers are typically used to clean up welds and slag. The conclusion was that while the scaler was an effective means to dislodge the saltcake material that may be attached to the tank liner, it was not effective in dislodging/mobilizing sludge simulants.

Air jets and waterjets in a scarifier configuration were tested and evaluated by Leist (1990). Air jets showed promise for sludge and soft saltcake dislodging because, in addition to their cutting capabilities, they are adept at 
breaking up the surface for conveying ease. However, air jets did not work well for hard saltcake removal. Waterjets, on the other hand, easily dislodged hard saltcake and were thus recommended for further development as a scarifier. Based on single- and multiple-jet tests, it was concluded that a multiple-jet configuration may be more effective for saltcake dislodging.

\subsubsection{Conveyance Feature Tests}

A positive displacement pump commonly used in the food industry was evaluated (Squires $1990 \mathrm{~b}$ ) for the conveyance of sludge simulants. Two sludge simulants were tested on a positive displacement pump. One simulant was thick (peanut butter consistency) while the second simulant was not as viscous (suntan lotion consistency). This type of pump was capable of pumping the materials, but some of the pump parts sustained a high degree of wear.

Initial testing of an air conveyance system (Thompson 1990) proved the method effective for retrieving simulated sludge. The system tested was somewhat small in size/capacity for some of the tests performed but showed that the technology is a sound option for waste retrieval with some modifications to the basic design.

It was suggested that a system using a fluid injection device at the feed nozzle and additional injection units placed along the hose runs may be necessary to prevent plugging of the conveyance line.

\subsection{Technology Peer Review}

In 1991, a multilaboratory and contractor team participated in a peer review (TRAC-0247) of the development work up to that time. The peer review concluded that pneumatic conveyance as well as waterjet dislodging development and others should proceed. Another important conclusion of the review was that future assessments of manipulators, end effectors, sensors, remote control equipment, system integration, and retrieval operations should be coordinated with the robotics technology development. This natural evolution from evaluating individual components of the retrieval system to careful consideration of the overall system allowed for additional focus of testing and development activities.

\subsection{Retrieval Technology Dem- onstration}

As part of the technology development efforts, an integrated technical demonstration was held in 1992 (Jaquish 1993) that demonstrated the use of various technologies in a single-shell mockup test bed. End effector tests included the soft waste dislodging and conveyance test apparatus, which consisted of a low-pressure waterjet soft waste dislodging tool coupled with an air conveyance system. This was the first attempt at integration of the dislodging and conveyance system. The test article effectively removed and conveyed the sludge over prototypic vertical lift and lateral runs at greater than target rates.

A hydraulic impact end effector demonstrated the ability to fracture saltcake simulants into fragments for removal. This end effector uses low-volume ultra-high-pressure blasts of water.

\subsection{Recent Development}

Further development has occurred since 1992, continuing to focus on those technologies that show high probabilities for success. Results from recent tests have indicated that scarifiers using high-pressure waterjets could effectively dislodge both sludge and saltcake. Furthermore, the use of air conveyance was enhanced by the fact that sludge simulants could be transported as effectively as "dry" scarified saltcake particles. 
In 1993, plans were laid out to start the integration of dislodging and conveyance technologies so that performance could be measured and design guidance generated. Those efforts became focused on providing retrieval performance data for separate and integrated dislodging and conveyance systems, in support of the first-generation retrieval system for Tank C106.

A strategy (Bamberger et al. 1993) was developed to guide an analytical/experimental approach to develop a multifunction scarifier dislodger coupled with a pneumatic conveyance system. The strategy was developed through review of existing theories and past experiments conducted under similar conditions. The review indicated that saltcake appears to be the easiest waste form to retrieve. Deformable, adhesive sludge is anticipated to be the most difficult to retrieve. No theories, correlations, or data exist to predict performance in this medium. Viscous liquid is anticipated to be of intermediate complexity to retrieve. Pneumatic transport of viscous liquids should be analogous to classical two-phase, gas-liquid flow.

Additional tests performed in FY93 substantially advanced the understanding of the processes required to remove waste from tanks. Scoping tests were conducted to determine which of the candidate technologies are likely to be capable of meeting EM 30's waste retrieval needs at Hanford (e.g., average of 30 gpm waste removed for sludge and saltcake).

The FY93 WD\&C testing program demonstrated that waterjet-based dislodging systems should meet EM 30's needs, provided that certain operational constraints can be met (Powell 1994). Further, preliminary examinations were conducted of two types of waste conveyance system (jet pump and blowerpowered conveyance systems); both were found to offer certain advantages.
Based on test results from University of Missouri-Rolla (UMR), Pacific Northwest Laboratory (PNL), and Quest Integrated, Inc. (Quest) for the depth of waterjet cut into saltcake simulant as a function of jet pressure, nozzle diameter, and traverse speed, it appears likely that a waterjet-based retrieval system can be designed to meet the EM 30 target of a $30-$ gpm average waste removal rate. The UMR data predict that a saltcake removal rate of 30 gpm could be attained using 10-ksi, 40-gpm waterjets. The PNL/Quest team, which evaluated ultra-high-pressure (50-ksi) waterjets and the data, predict that the 30-gpm target can be met using 50-ksi jets at a flow rate of much less than $\mathbf{4 0} \mathbf{g p m}$ of added water (Pezzimenti 1989; Quest 1990). It must be stressed that these predictions were based on preliminary laboratory data and may change as more data are generated.

As part of the development of the soft waste dislodging unit, Westinghouse Hanford Company (WHC) engineers used a "negative pressure" pneumatic waste conveyance system with water lubricant to transport the dislodged sludge simulant. The dislodged simulant chunks, shreds, and ribbons were conveyed at super-prototypic rates through a 60 -ft vertical rise as well as through a horizontal run, to simulate the geometry expected during SST retrieval. Previous testing of this type of air conveyance system with the adhesive, cohesive, hydrophilic sludge simulant demonstrated that unless water was introduced at the conduit entry interior surface, the conveyance line would accumulate sludge simulant and plugging would result.

The WHC team demonstrated the ability of its integrated soft waste dislodging unit and air conveyance system to mobilize and convey sludge simulant at approximately $95 \mathrm{gpm}$ with a water flow rate of less than $7.5 \mathrm{gpm}$. These high retrieval rates were sustained for only about 15 seconds due to the small size of the test bed. Further testing is required to determine whether these high retrieval rates can be 
sustained for long-term, steady-state waste removal operations. During the testing, the conveyance line was visually observed to flex and jump as pieces of sludge simulant were transported. Quantifying the magnitude of the forces that might be applied to a robotic arm from the conveyance line movement is an objective of future testing.

An alternative conveyance system for dislodged waste is being developed by the UMR team. This system uses a modified version of a commercially available jet pump to provide the suction that lifts the dislodged waste from the tank. Once the dislodged waste is entrained in the air entering the conveyance system end effector inlet, it passes only a short distance through the conveyance line before flowing through the jet pump throat. Several 10-ksi waterjets are focused in the jet pump throat, and these waterjets will cut up any pieces of sludge or saltcake large enough to become lodged in the pump throat. The resulting gas/slurry/solid mixture is pushed up through a 2-in.-diameter conveyance line by the momentum imparted by the waterjets. The ability of this modified jet pump to produce the required pressure and flow rate was demonstrated by the UMR team in FY93. It is not yet known how the jet pump conveyance system compares to the blower-powered system in terms of tolerance for variable stand-off distance and entrained air flow rate or reaction forces on the robotic arm. The jet pump system offers the benefits of a smaller conveyance line (compared to the large diameter required for pneumatic air conveyance) and relatively constant mass flow rate, given that the density of the fluid conveyance medium is closer to that of the waste than that of air. 


\subsection{System Description}

A general description of the system recommended by the WD\&C program is provided here. The actual configuration of the hardware to accomplish the dislodging and conveyance functions will be established by vendors of the first-generation system. The definition of methods to deploy the dislodging end effectors and conveyance system elements in the tank is beyond the scope of this recommendations document. It is assumed that they will be deployed inside the tank by some type of arm-based maneuvering system, the LongReach Manipulator (LRM).

The methodology of attaching and detaching the end effectors to/from the maneuvering arm, and the routing and attachment of the services to them, will also be established by the selected vendors. It is anticipated that the method of end effector attachment, detachment, and service routing will not have significant impact on any development work done up to that time and can readily be incorporated into the vendor designs.

Detailed requirements for the dislodging and conveyance system equipment are not specifically within the scope of this document. In general, however, the equipment must be tolerant of impact, radiation and caustic materials, abrasion and wear of moving parts and parts exposed to the waste stream and dislodging action, and decontamination procedures. Components and systems must have service lives predicted by recognized methods and supported by empirical data from similar equipment, sufficient to campaign a tank without service. Potential in-tank damage or failure modes must be entirely serviceable by remote handling methods and not impair graceful recovery of the entire retrieval system.
The two major subsystems--disloding and conveyance--are described in the following sections.

\subsection{Dislodging System}

\subsubsection{Functional Description}

The waste dislodging system is the equipment-the end effector, which interacts directly with the waste to separate a stream of waste from the body of waste in a form acceptable, and in a trajectory accessible, to the conveyance system-and the ancillary power supplies and . controls necessary for operation of the end effector. Different equipment may or may not be required for different types of waste. The research conducted to date by the WD\&C program indicates that a single end effector can be designed that will be effective on all predicted waste forms; however, this has not been demonstrated.

The dislodging system must remove waste at a sufficiently consistent rate to support the required productivity of the system, to facilitate planned-path operation, and to impose manageably steady loads on the deployment system. The end effector(s) must effectively mine the various waste materials from the bulk tank contents; clean the tank walls, including stiffening rings; clean the tank floor and radiused corners, possibly including buckled and corroded plate; and clean large in-tank hardware. A process schematic diagram for the dislodging system is shown in Figure 4.1.

\subsubsection{High-Pressure Waterjet Equip- ment Description}

The baseline technology for waste dislodging is a high-pressure waterjet scarifier. Highpressure waterjet technology has been used industrially for many years for mining, cut- 


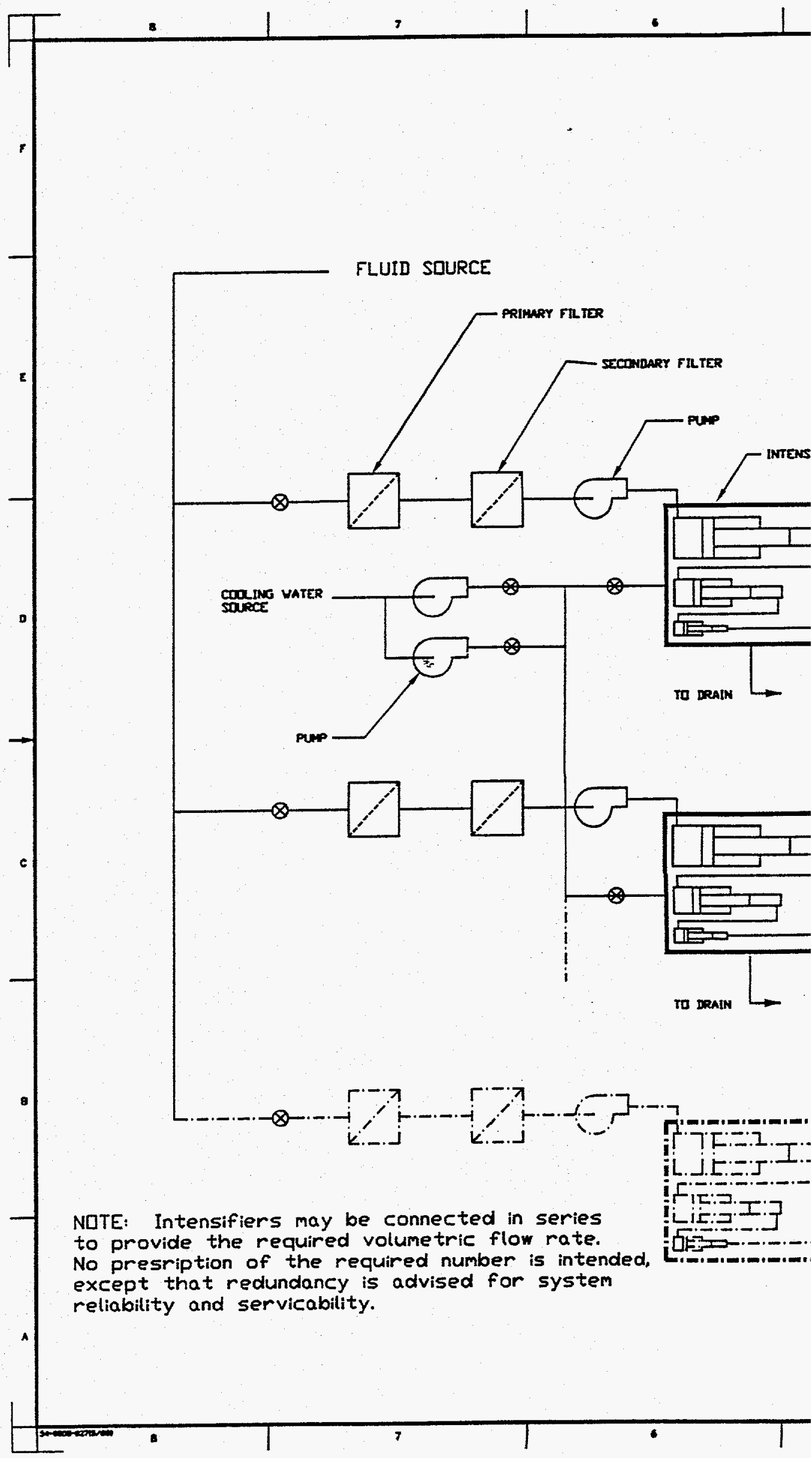

Figure 4.1. Process Schemati 


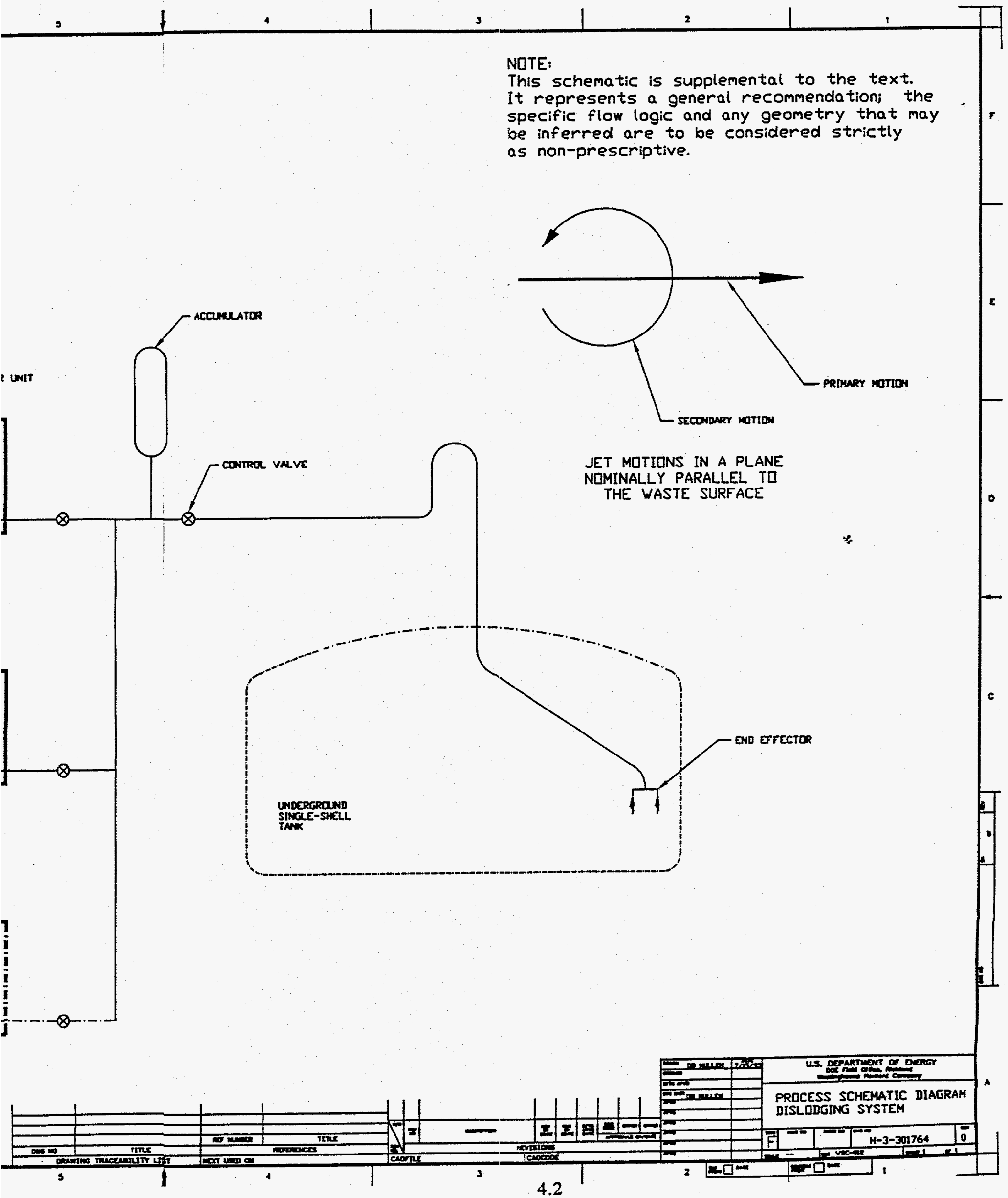

Jiagram for the Dislodging System 
ting, cleaning, and scarification of materials with a broad range of properties. Separate effects and proof-of-concept testing conducted by the WD\&C program have demonstrated that high-pressure waterjets can effectively dislodge several diverse waste simulants.

The high-pressure waterjet end effector will consist of high-pressure fluid jets mounted on a rotating body and directed at the waste surface. The rotation of the jet carrier is provided by a secondary motion drive. The axis of secondary motion rotation is nominally normal to the waste surface. The secondary motion drive and jet carrier are contained in an aerodynamically faired enclosure mounted concentric to and inside the conveyance system inlet shroud. The whole assembly is mounted to an interface plate, half of which mates to another half on the manipulator arm. The ancillary components of the system include the fluid pressure hose(s), on-off valve(s), pumping unit(s), and other support equipment.

Design features of the system include those described in the following subsections.

\subsubsection{Waterjet Nozzles}

Waterjet nozzles are constructed of hard, abrasion-resistant materials. The orifices are configured to produce jets of the required pattern, all variations on the cone: cone, line or round, and fan. Jets of different pattern and orientation can be combined to interact to increase productivity. It may prove beneficial to adjust the orientation of the jets for different wastes or functions (e.g., mining vs. surface cleaning).

In hard, friable waste simulants, round jets exhibit deep penetration as a function of pressure. The primary dislodging mechanism is erosion, limiting productivity of single jets and single passes. Multiple round jets given circular secondary motion, coordinated with the primary traverse motion to closely space successive kerfs, give high productivity due to secondary fracture; the inter-kerf "ribs" fracture off in chunks. If the jets are angled radially outward from the axis of circular secondary motion, the secondary fracture is reinforced by the overlapping and intersecting curved kerf surfaces. This technique reduces the sensitivity of the process to coordination of secondary and primary motion to control kerf spacing. This configuration is considered by the researchers to be both most demonstrably productive and most promising for refinement. Test results supporting this judgement are not released for publication at this time; they should be available in early FY95.

Round jets penetrate deeply into sludge, and the kerf tends to heal immediately. However, low-pressure (100- to 1500-psi) round jets inclined radially inward and given coordinated oscillating circular secondary motion and linear primary motion have demonstrated the highest productivity of any system tested to date on sludge when coupled with an air conveyance system that constantly pulled the cut material away and precluded contact of the cut surfaces (Thompson 1993). The sludge was observed to be stripped away in short ribbons or scallops. The motions used in these tests created fragments with major dimensions ranging from 2 in. to 10 in., so they were not optimal for air conveyance. Adjustment of motion variables would produce smaller fragments. High-pressure jets and jets directed radially outward have not been tested in this mode. They may behave similarly. However, the high-pressure jet is much smaller and the flow rate lower per unit of kerf surface, so lubrication, mobilization, and transport effects may be unpredictable. Further testing in FY95 will address this issue.

High-pressure fan jets are effective at dislodging sludge, and dislodging productivity can increase with stand-off distance. Single-effects high-pressure tests indicated that combined fan jets were the most productive combination for sludge. High-pressure fan jets have not been tested on sludge with pneumatic conveyance or 
secondary motion. In the low-pressure testing with secondary motion and conveyance, the round jets were found more effective than fan jets.

\subsubsection{Secondary Motion Drive}

The dislodging system end effector will be equipped with a secondary motion drive to permit translational or rotational motion of the jets within the end effector, approximately in the plane of the waste surface, independent of or coordinated with the motion of the LRM. The motion should not be driven by the waterjet thrust but be independently driven and controlled. This will permit adjustments to the secondary motion speed to accommodate fluctuations in the manipulator speed or variations in the waste form. Test results indicate that there will be an optimal nominal ratio of the speed of the secondary motion to the end effector transverse velocity, which will result in dislodging of waste in particles of the appropriate size distribution for effective conveyance. (The optimal particle size may vary for different waste forms; therefore, it is not specified here.)

\subsubsection{Interface Plate}

The end effector will be attached to the manipulator with an interface plate to enable remote change-out. The interface plate will transfer loads and provide connection of utilities including hydraulic lines, electrical power, conveyance line, and sensor and control conductors to the end effectors. It may be necessary for the interface plate to incorporate forcelimiting, self-restoring compliant joint functionality to protect the end effector and arm from damage in the event of impacts.

\subsubsection{Ultra-High-Pressure Hose}

Ultra-high-pressure (UHP) lines will transfer the high-pressure water from the pumping units to the end effector. The lines will be rated for a continuous working pressure of
60,000 psi. A combination of flexible UHP hoses and swivels will be used to accommodate the motion of the LRM. A recent study by Holden and Monserud (1993) indicates that this is technically feasible. At the end effector, the UHP hose will be secured to structural members of the LRM such that it is not subjected to direct structural loading. The number of elbows and swivels and the total line length will be minimized to reduce the pressure drop between the pumping unit and the end effector.

\subsubsection{High-Pressure Fluid Valves}

These valves will control HP fluid flow in the system. They must minimize water hammer effects and vent line pressure outside the tank when required.

\subsubsection{Pumping Units}

The pumping units must supply the high-pressure fluid at up to $55,000 \mathrm{psi}$. The flow rate at 55,000 psi will be approximately $15 \mathrm{gpm}$. Operation at lower pressures requires proportionally greater flows. The inlet fluid to the pumping units must be well-filtered, typically to 1 micron. These pumping units are commercially available as integrated systems consisting of an electric or diesel power supply and a parallel array of high-pressure intensifiers as needed to provide the required volumetric flow rate. The pumping unit will be equipped with an accumulator between the intensifiers and the flow control valve to reduce pressure fluctuations.

\subsubsection{Control System}

The dislodging system control subsystem must coordinate with the manipulator and conveyance control subsystems and the supervisory control system to

- Coordinate secondary motion of cutting jets with primary motion, to control particle size. 
- Coordinate fluid flow rate with motions to control particle size, cut depth, and dislodging rate.

- Sequentially start and shut down conveyance and fluid jets, to control free fluid introduced to the tank and loading of the conveyance system.

- Detect leakage in the HP system and shut down and vent the system in the event of a detected leak.

- Monitor pressures and flow rates at the pumping unit and the end effector.

\subsection{Convéyance System}

\subsubsection{Functional Description}

The conveyance system receives material from the end effector(s) and transports the material to an above-ground interim storage/transfer facility where it can be further processed and passed to downstream functions.

The waste conveyance system must be able to convey a waste stream having a wide variety of properties. Due to the heterogeneous nature of the waste, the waste stream produced by the end effector may be wetted granular solids, viscoplastic sludges, slurries, or liquids. The particle size and shape will vary from fine mists to ribbons and slugs. Some materials may be adhesive or cohesive, tending to plate onto the conduit or agglomerate into larger particles. The conveyance system operating parameters should be controllable to adjust the system to various waste stream properties.

The waste conveyance system must include means of coping with off-normal conditions, including loss of primary power, presence of oversized elements in the potential waste stream, intermittent or extensive periods of inlet blockage, blockage in the conduit, submersion of the inlet in liquid, and erratic variations in the waste stream characteristics. The system must have the capability to gracefully recover from any failure mode. A process schematic diagram for the conveyance system is shown in Figure 4.2.

\subsubsection{Pneumatic Equipment Description}

The pneumatic conveyance system is, in principle, very similar to a conventional shop vacuum cleaner on a large scale, with features to enhance reliability and flexibility.

The pneumatic conveyance system components include the shroud, discriminator, conveyance line, flow lubrication system, bleeder system, waste stream separator, vacuum blower, discharge system, and control system. The overall system operates under partial vacuum, with a blower drawing air through the system. For longevity of the blower and minimization of maintenance personnel exposure to radiation, the blower should be at or near the downstream end of the system, with all separators and filtration on the inlet side.

In the event of primary power loss, the system must either provide immediate backup power to sustain continuous flow or have demonstrated capability to re-start flow of any waste stream residual in the conduit.

The system may be pressurized to blow down the conveyance line and clear the inlet discriminator. All components must be designed for the blowdown pressure (10 psig) and operating pressure ( 5 psia).

\subsubsection{Inlet Shroud}

The waste stream dislodged by waterjet end effectors will be a mixture of particles, fluid droplets, and mist propagated from the jet impact point with a high range of speed and direction. To capture this spray of material, prevent it from obscuring visibility in the tank, and effectively entrain the waste stream into 


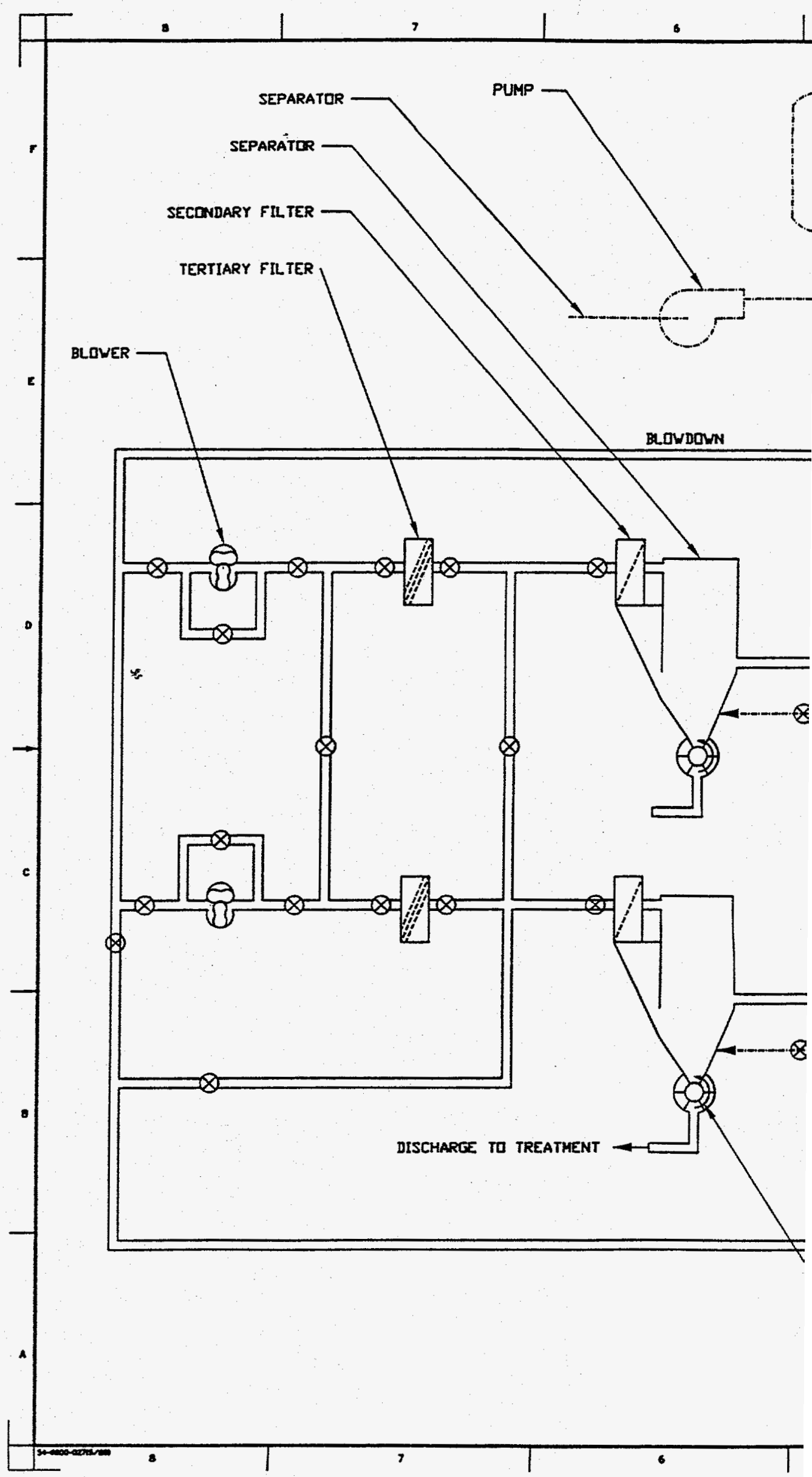

Figure 4.2. Process Schematic 


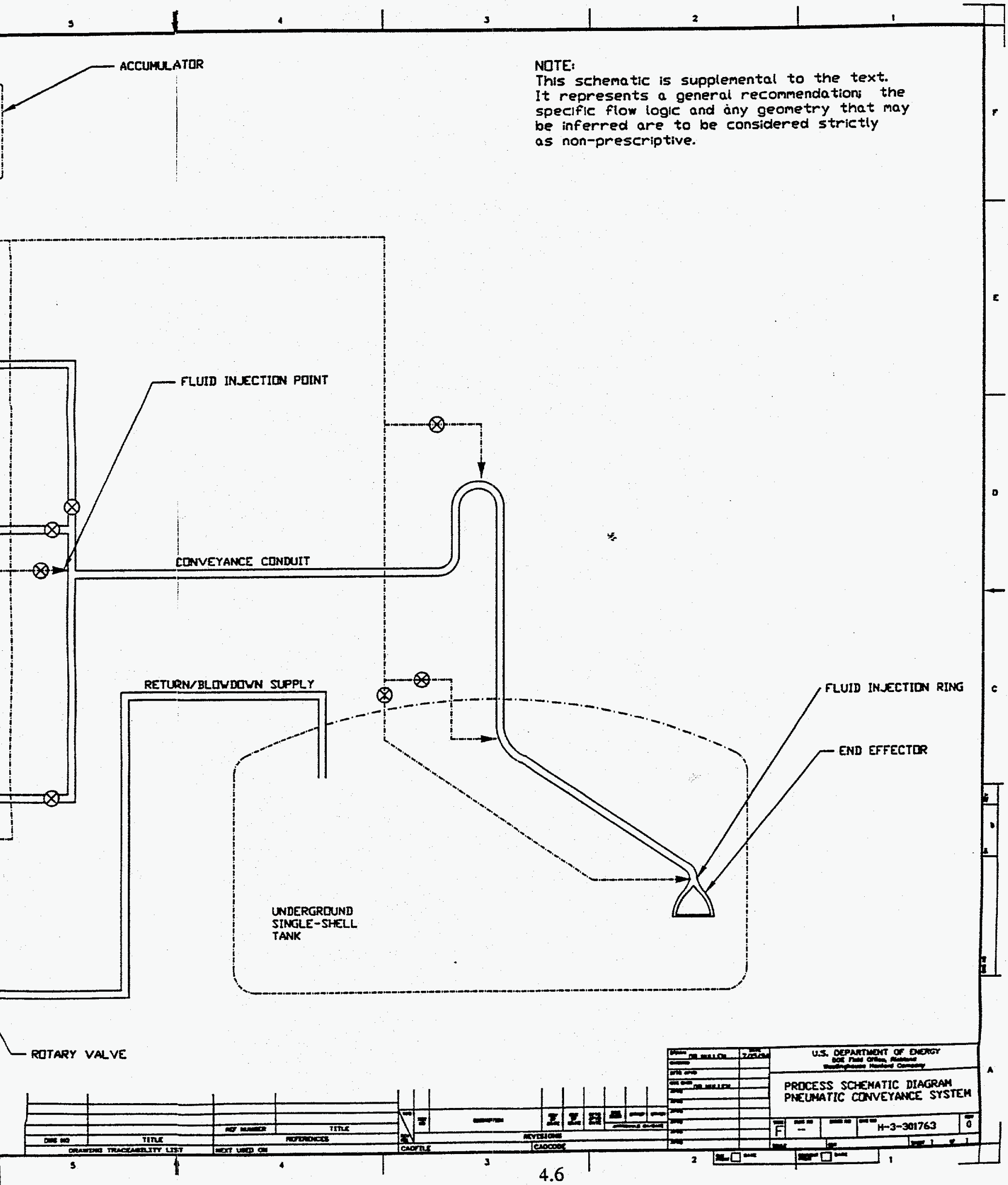

piagram for the Conveyance System 
the conveyance airstream, an inlet shroud is required around the working area of the dislodging process and the conveyance line inlet. The inlet should generate adequate airflow velocity at the waste surface to entrain dislodged but static waste or fluids lying on the surface while the end effector is within a range of stand-off distances from the surface that can be maintained by the manipulator under normal operations.

This shroud may be annular to the waterjet head, integral with the waterjet head, or asymmetrically arranged. The shroud must be robust enough to withstand accidental impacts and abrasion from the waste stream. The requirement of an inlet shroud may be met by other devices demonstrated to effectively perform the functions. The configuration of the shroud should not be such that a traverse directional bias is established for the end effector; the end effector should function acceptably when moving in any direction.

The shroud must incorporate passive or active features to limit the force normal to the waste surface due to pressure differential across the shroud and thereby protect the deployment system from overload and control difficulty.

Testing and development of inlet shroud configurations is continuing in FY94 and FY95. Specific design guidance and test reports will be available.

\subsubsection{Conveyance Conduit}

The waste stream is to be confined to a conduit between the end effector and the surface separation unit. The conduit must accommodate the variable geometry of the deployment system, the various attitudes required of the end effector for tank wall feature cleaning and mining, and the deployment and retraction of the manipulator arm. It must have sufficient abrasion, chemical, fatigue, thermal, and radiation resistance to satisfy service life re- quirements. A length of up to $150 \mathrm{ft}$ is contemplated.

The interior diameter of the conduit may vary over the length, expanding in the direction of flow to reduce terminal velocity. The diameter will be approximately $10 \mathrm{in}$. at the inlet; however, materials, inlet and conduit geometry, and other features will influence the design.

Bends required in the conduit may be achieved by flexible hose sections or swivel elbows. The latter may require higher air velocities to keep material in suspension through two $90^{\circ}$ bends in succession and will incur greater pressure drops but may offer better and more predictable wear rates than hose. Ongoing testing by the WD\&C program is planned to provide further design guidance for bends.

Valves and tees at the inlet to the separator are to be fitted to allow for blowdown. The conduit must withstand the maximum blowdown pressures available with appropriate safety margins.

Sections of the conveyance line may have to be inclined to accommodate the deployment system geometry and mining strategy. This is not generally recommended practice for extended pneumatic conveyance lines, but it is common to use a short inlet hose in almost any geometry. Ongoing testing by the WD\&C program is planned to provide further design guidance for inclined lines.

\subsubsection{Inlet Discriminator}

The conveyance system must include a discrimination mechanism located at the inlet, to prevent any material of an unacceptable size and configuration (e.g., steel tapes, wires, sheet metal) from entering the conveyance line, to minimize the potential for flow blockage. The discriminator must be self-clearing of any normally intercepted material without having to be removed from the tank. Howev- 
er, should self-clearing mechanisms fail, the discriminator shall be designed to be easily cleared out using remote techniques either in the tank or the operational support facility.

\subsubsection{Lubrication System}

Testing (Thompson 1993) with adhesive, cohesive simulants (kaolin clays) has demonstrated that such material may plate onto the conveyance line walls, constricting and possibly plugging the line, resulting in surging flows or failure. Introduction of a lubricating fluid (water) in a low-pressure/volume spray by means of a set of nozzles arrayed around the inlet perimeter mitigated this effect quite successfully. Pending characterization of the tank wastes, it should be assumed that some wastes will require such lubrication for transport. It is thought, but not yet confirmed by testing, that introduction of small flows of lubricant at several critical points in the line (bends, transitions) may be more effective than introduction only at the inlet and would offer greater flexibility for effective lubrication with minimum fluid consumption. Lubricating fluid injection points should be individually controllable to prevent the unnecessary addition of fluid. Recycled process or tank fluids may be suitable for lubrication; the lower pressures required may be provided by simple, lowmaintenance pumps.

\subsubsection{Bleeders}

Continuous flow of air in the conveyance system should be maintained whenever waste material is in the conduit to prevent the settling of material with consequent restart difficulties. Self-opening air bleeds may be provided at various locations along the length of the conveyance line, to sustain flow downstream from a blockage.

\subsubsection{Waste Stream Separator}

The waste conveyance system will include a separator to separate the liquids and solid waste from the transport air in the conveyance line. A cyclonic primary separator is considered the best approach for this application; however, measures to mitigate adhesion of waste to the collector walls are recommended, such as fluid lubrication and/or mechanical scrapers. Secondary separation, usually provided by bag filtration or rigid filters, should be tolerant of moisture and mists of waste in suspension. Secondary separators should be arranged in parallel to allow continuous operation during cleaning cycles. Filters used should be cleanable in situ to reduce operator exposure and production of secondary waste. The separators are mounted atop collectors of sufficient capacity to buffer the flow into the downstream processing.

Discharge of waste from the collector may be continuous, through a rotary airlock valve or through sequential pinch, slide, or gate valves, or batched through single valves. For continuous operation, batch discharge will require at least two separators and collectors in parallel. It is suggested that two complete primary and secondary separators with continuous discharge systems be arranged in parallel, with crossconnection to allow operation with any combination of primary and secondary units.

The separator outlet to the blower will be the lowest-pressure point in the system. Provision should be made to trap and collect any condensate formed downstream of the tertiary filters as well as any fluid leakage through the filters.

\subsubsection{Vacuum Blower}

The airflow will be driven by a blower or combination of blowers. Redundant blower capacity is suggested. The blower(s) are to move more than $3,500 \mathrm{ft}^{3} / \mathrm{min}$ of air through the system, with a minimum operating pressure of about 5 psia or 20 in. of vacuum. Positive-displacement blowers are recommended as they are more tolerant of inlet restriction. The blowers must be capable of supply- 
ing 10 psig pressure to blow down the conveyance line and backflush the discriminator.

The blower(s) are to be downstream of the separator/filter system to protect the blower(s) from abrasive wear. Tertiary filtration may be advisable to protect the blowers from catastrophic secondary filtration failure.

\subsubsection{Air Discharge}

Closed-loop discharge of the process air back to the UST is recommended. Process air must be considered contaminated, so discharge to the atmosphere will require extensive filtration resulting in generation of significant secondary waste. Appropriate venting of the UST will be required to ensure that no significant pressure differential is generated. Discharge from the blower will be slightly above atmospheric pressure, so safeguards against leakage must be provided.

Discharge from at least one blower should be valved and connected to the conveyance line near the separator inlet to allow blowdown of the line to clear the discriminator. Tank venting must be sized to accommodate blowdown airflow.

\subsubsection{Control System}

The conveyance system control subsystem must coordinate with the manipulator and dislodging control subsystems and the supervisory control to

- Coordinate airflow with dislodging rate to provide effective conveyance without unnecessarily high velocities, wear rates, and power consumption.

- Sequentially start and shut down conveyance blowers, lubrication system, and HP fluid jets, to control free fluid introduced to the tank and loading of the conveyance system.
- Monitor pressures and flow rates at critical points.

- Coordinate valve operation for blowdown and selection of operating equipment, to preclude uncontrolled discharge to the atmosphere.

\subsection{System Integration}

The primary challenges for integration of the waste dislodging and conveyance system are the coordination of the two elements and the integration of the system with the manipulator.

Coordination of the WD\&C system elements is discussed extensively in the preceding sections. To summarize, the issues are as follows:

- coordination of airflow and conveyance system capacity with dislodging rate - Nonhomogeneous waste may cause erratic dislodging rates, and the conveyance system may not be responsive enough to the changes; therefore, it is probable that the conveyance system must be oversized and operated at less than capacity (i.e., in more dilute-phase mode than ideal). This will result in considerable energy inefficiency and is to be mitigated to the extent possible consistent with reliable operation.

- design of end-effector interface - The bulky conduit and the inlet shroud and discriminator must be mated to the dislodging end effector without compromising either system. Flexibility of operation and range of motion should not be limited more than necessary. The end effector should not have any traverse-directional bias; it should be able to traverse in any direction while working efficiently and to operate close to obstructions from any side. 
Coordination of WD\&C systems with the manipulator/deployment system raises the following issues:

- spatial control of the end effector The dislodging system and the inlet of the conveyance system are both sensitive to the distance from the surface. The best productivity can be achieved with minimal stand-off distances; however, the following factors make it difficult to maintain minimal stand-off:

- Downforce due to the pressure differential across the inlet shroud is expected to be an inverse function of stand-off distance for any practical shroud design.

- Dislodging rate is also an inverse function of stand-off distance; therefore, the inlet mass flow rate and mass acceleration will be functions of stand-off distance.

- Dislodging rate and corresponding forces are a function of the inhomogeneous material properties.
- Irregular surface contours both before and after mining/milling of the surface make responsive contour-following necessary to control stand-off distance. This requires either or both detailed, high-resolution surface mapping for planned-path operation or near-real-time proximity sensing and control/arm response.

- Momentum transfer, friction, and pressure forces in the conveyance line will inconsistently disturb the positioning of the manipulator.

geometric constraints - Bends and inclined sections are undesirable in the conveyance line but required for dexterity of the manipulator. Balancing the requirements of the two systems will be a significant challenge. The conveyance system may exhibit nonlinear response to geometric parameters, with dynamical catastrophe lurking around every bend and corner. 


\subsection{Technology Development Focus Areas}

During FY93 and previous years, significant progress has been made through a series of feature tests and demonstrations of mediumpressure (10,000-psi) and high-pressure (55,000-psi) waterjets for dislodging of the waste material and pneumatic suction and waterjet pumping systems for conveyance of the waste out of the tank to the next step of the process. At the conclusion of FY93, the WD\&C team defined open technical issues remaining before concepts could be bounded. In parallel, EM 30 end users and laboratory developers convened coordination activities to define the interface needs between project and development entities supporting SST waste retrieval. The WD\&C testing program has been focused on addressing these technology needs for the first-generation retrieval system. The needs identified to date are summarized below. These needs were used to establish eight focus areas that comprise the WD\&C testing program; these focus areas are described at the conclusion of this section.

\subsection{Waste Simulant Development for Process Qualification}

\subsubsection{Technical Background}

Waste dislodging and conveyance processes will require system qualification tests using actual radioactive waste materials or simulated waste. Testing with radioactive waste has disadvantages involving the volume of material available, significant hazards to personnel, and high cost to run tests. The use of simulated waste in the development of technologies for dislodging and conveyance in support of the first-generation retrieval system is promoted to overcome these disadvantages.

However, the application of simulants is not without its difficulties. An analysis of the sensitivity of waste mobilization and convey- ance processes to simulant properties must be conducted so that waste simulants that challenge the process over the broad range of anticipated in-tank wastes can be designed. This knowledge can be gained through expert or historical knowledge, or may be gained by postulating key parameters and then developing simulants to test the sensitivity of the process to changes in the parameters. Each process requires a different type of simulant, depending on the process sensitivity to the physical properties of the waste. Waterjet mobilization, for example, is expected to be sensitive to tensile properties and porosity, while certain mechanical systems may be more sensitive to shear strength. Air conveyance performance is largely dependent on the proportion of fines and the amount of water in the system. Because no one simulant can represent the extremes of each physical property, simulants are developed and tailored to the waste mobilization and conveyance processes. The WD\&C simulant strategy is described in detail and is depicted in the flowchart shown in Figure 5.1.

Characterization of waste inside Hanford underground storage tanks is very limited and may not span relevant waste properties. Until such time that physical characterization data becomes available for the actual tank wastes, the simulant properties must be carefully designed to expose the limitations of the process and span the range of properties expected to be critical to the processes studied. In this manner, testing with simulants will minimize the process development effort and help minimize and focus waste characterization efforts.

\subsubsection{Conclusion}

Tailored simulants can be developed that are, in essence, qualified through the process as opposed to qualification based on characterization data. The dislodging or conveyance 


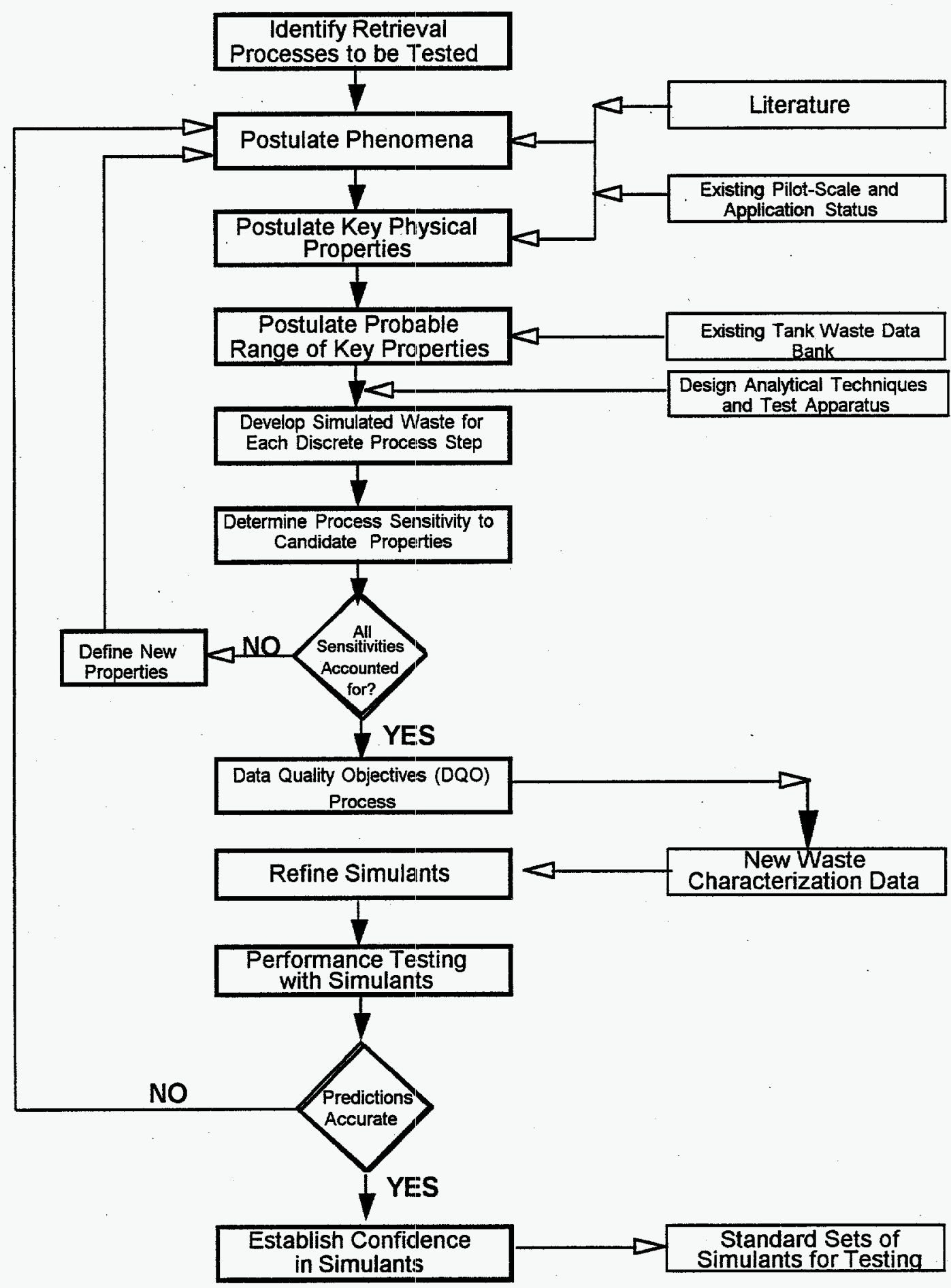

Figure 5.1. Simulant Development Strategy 
technologies are tested to determine sensitivities to key physical properties of the simulants. These key physical properties can be varied by manipulating the simulant recipes. The simulants will be qualified by establishing correlations between process parameters and simulant properties.

\subsection{Mining Strategy}

\subsubsection{Technical Background}

A process deployment strategy will be required to cope with changes in the surface contours of the waste. This shall include addressing the problems of capture of dislodged waste and spent water over uneven terrain, avoiding collisions with the waste surface, and procedures for maintaining effective stand-off distance over an uneven surface. Initially, it is expected that the topography of the waste surface will be irregular, with "hills and valleys." The mining strategy chosen for the retrieval must be such that a high average retrieval rate is maintained. The overall strategy must effectively retrieve waste over the existing topography as well as any "tool-made" topography that may include ridges, knobs of harder material, loose chunks, or leftover ribs from previous passes over the surface.

Two approaches to dealing with changes of topography have been considered. The first approach is one in which the dislodging and conveyance system are terrain followers. The control system senses the surface real-time or has prior knowledge of the "hills and valleys" within the tank. The retrieval system then would follow the terrain and maintain a constant stand-off distance from the surface to the extent possible. In this approach, the system would be constantly changing the topography as a hill or valley is cut down. Therefore, the system would have to continue to either sense these changes real-time or have other mapping systems that update the retrieval control system.
The second approach is based on a horizontal milling strategy to remove the waste. The essence of the approach is to mill the hills down to a relatively flat surface. Initially, this approach also requires prior knowledge of the waste topography or the ability to sense the topography real-time. Once a relatively level surface of waste remains, the retrieval system can begin normal mining operations. When milling of the initial irregular topography is performed, there will be some loss of retrieval performance. The extent of loss will be dependent upon the size of the scarifier unit and the ability of the deployment system to maintain the shroud at a close stand-off such that the conveyance system can lift the dislodged particles out of the cutting area. Any particles that are not retrieved will fall into a valley and will be retrieved later during normal mining operations. A draft mining strategy concept utilizing the horizontal milling approach has been developed by the University of MissouriRolla.

\subsubsection{Conclusion}

Initially, the contour-following approach allows for high retrieval rates by following the terrain. However, at this time, terrain sensing, especially in real time, and autonomous path modification technologies are not sufficiently developed to allow immediate application. Adequate mapping of the tank and waste surface via other monitoring and characterization systems also requires further development for this application. Both control information technologies have been developed to some level of maturity by DOE-funded projects and elsewhere. Furthermore, when the bottom of the tank is reached, the effective retrieval rate will drop significantly when hills remain to be retrieved.

The horizontal milling approach starts with a lower effective retrieval rate. However, once the hills are milled flat, the normal mining operation becomes a very repetitive process 
that is simpler to control, monitor, and maintain. The effective overall retrieval rate will be higher for a simpler, less complex control system for normal operations.

In any case, the varying hardness of the waste (and the possibility of hard inclusions) may result in an irregular depth of cut and an unpredictable post-cut surface. Whether the contour-following or the milling strategy is used, some degree of terrain sensing will be required to prevent collisions with projections remaining from the surface.

\subsection{Maintaining a Constant Stand-Off Distance}

\subsubsection{Technical Background}

The accuracy, repeatability, and maneuverability requirements to implement mining strategy and achieve desired retrieval rates must be established. These requirements will be driven, in part, by the tolerance of the stand-off distance required to maintain the target retrieval rates. The conveyance system concepts studied to date require a fairly constant standoff distance ( \pm 1 in.). The waste dislodging and conveyance end effector design must be tolerant of variations in the stand-off distance such that unreasonable requirements are not placed on the deployment platform.

\subsubsection{Conclusion}

The stand-off distance requirements of the end effector will dictate the accuracy, repeatability, sensing, and control requirements of the deployment arm. In addition, the end effector will apply dynamic loads to the arm that could excite its natural frequencies and result in oscillations that must be controlled.

\subsection{System Dynamics}

\subsubsection{Technical Background}

The waste dislodging and conveyance system will be integrated with a manipulator having some degree of structural flexibility. The interaction between the waste dislodging and conveyance system and the manipulator must be evaluated so responses to dynamic loading can be well understood and mitigated. Regardless of whether pneumatic conveyance or waterjet conveyance is chosen for retrieval, proximity of the inlet to the waste surface will have a significant effect on the performance of the conveyance system and on the forces imparted to the arm.

The candidate manipulator designs are long and flexible, so dynamic loads will cause oscillation of the system affecting the position of the end effector. Therefore, dynamic forces originating with the dislodging and conveyance processes need to be understood prior to design of the system.

Dynamic forces will originate from several sources. Intermittent contact with a surface of irregular topography could excite the vibratory modes of the deployment platform and challenge its ability to maintain the required standoff distance. A significant load will be produced by the pressure differential across the inlet shroud. This will be a function of volumetric airflow rate, stand-off distance, waste surface texture, and inlet design. Waste mass flow rate and the rate at which the waste stream is accelerated in the inlet will contribute to normal forces at the end effector, as will reaction of the waterjets. The latter will be relatively continuous and controllable. Waste mass flow rate will be a stochastic function of waste properties, dislodging tool design, and operational parameters such as jet type, geometry, water pressure and flow rate, stand-off distance, and traverse/secondary motions. 
Another source of dynamic loads will be material moving through the conveyance line. Momentum transfer, friction, and bending forces in both conveyance and water supply lines will impart variable forces to the arm at each bend (if the lines are led along the arm) and at the end effector. Line flexural stiffness and nonlinear damping properties will also complicate control of the arm motion. A requirement for optimal pneumatic conveyance system performance is control of particle size.

Pneumatic conveyance is most effective and controllable when the particle size is small $(<3 \mathrm{~mm})$. Past tests on soft waste simulants have qualitatively shown that pneumatic conveyance systems will convey large globules and slugs of material. However, the flexible conveyance line, which was not restrained except at the ends of a 60 -ft section, experienced large oscillations. This can be mitigated through design of the dislodging system and the use of discriminators and additional cutting devices in the inlet to keep the particle sizes to a minimum.

Dynamic loads are induced as a jitter phenomenon that may result if the manipulator is traversing at a slow rate, due to joint stiction. This stiction may limit the minimum traverse velocity.

The largest potential for dynamic loading is during off-normal events. Off-normal events include running into a tank wall or tank bottom, burying the scarifier into sludge waste, collisions with large objects like rocks and tools that may be imbedded in the waste, sudden loss of power, sudden loss of airflow (for pneumatic conveyance), sudden loss of water flow (for waterjet cutting), operator errors, and others. The mitigation of these events is not well understood at this time, but knowledge will be gained as integrated testing gets under way.

\subsubsection{Conclusion}

Successful integration will occur through careful consideration of mining strategies, mitigation of dynamic effects, and an understanding of off-normal events.

\subsection{Potential for Tank Wall Damage}

\subsubsection{Technical Background}

Waterjet cutting tools at pressures ranging from 10,000 psi to 55,000 psi are candidate technologies currently undergoing evaluation. It is expected that during a retrieval campaign, the waste will be removed, leaving exposed metal on the tank wall and bottom. It is also expected that there will be some degree of corrosion of the metal, but no information available assesses the severity of tank corrosion. Retrieval activities will potentially degrade the structural integrity of the tank. Tank wall damage due to the manipulator system crashing into the bottom or the side walls of the tank is not considered in this issue statement.

Information to date was collected during testing conducted by the University of MissouriRolla under contract to Sandia National Laboratories during the last quarter of calendar year 1993. In these tests, the traversing waterjet was passed over solid simulant and "cracked" simulant lying over the simulated uncracked and simulated cracked degraded tank walls.

The thin-wall tests of the removal of saltcake down to a corroded uncracked metal surface have shown that the jets, at 10,000 psi and $0.032 \mathrm{in}$. diameter, will easily clean and remove the saltcake from the metal. The thinwall tests qualitatively showed that the waterjets would mobilize the waste without damaging the tank wall. 
The simulated cracked tank wall tests were conducted to determine whether water from the waterjets would flow readily through a simulated tank wall crack, as well as to see if the waterjet would cause the crack to propagate further.

The first series of tests simulated the end effector approaching the floor of the tank with the jets pointed perpendicular to the tank wall surface. An adequate bond between the simulant and the metal surface was difficult to obtain. Upon impact with the metal after the simulated waste was cut, the water from the jets simply flowed underneath the waste surface along the metal surface to the simulated crack and through the crack. Thus, the data from the cracked metal surfaces with the jets impacting perpendicular to that surface have shown rapid water penetration through the crack by the waterjets.

A second series of tests was completed with jets oriented at a steep angle to the metal surface, simulating the end effector approaching the side walls of the tank. In this series of tests, the jets were inclined at $25^{\circ}$ to the plate to simulate the wall. The jets now rebounded along the simulant surface after the penetration of the waste. The jets had to be positioned directly over the crack for water to penetrate through it.

In all tests performed, there was no sign of degradation caused by the waterjets. Furthermore, the waterjets did not cause additional propagation of a pre-existing simulated crack.

\subsubsection{Conclusion}

The use of nonabrasive waterjets to mobilize waste will not degrade the structural integrity of tank walls or tank bottoms during retrieval operations. Based on a series of qualitative tests performed at the University of MissouriRolla, degraded simulated tank walls were not additionally degraded in the presence of a waterjet. A series of thin-wall, cracked-wall, and fissured-simulant tests indicated that the tank wall material would not be degraded.

\subsection{Conveyance System Capability and Integration}

\subsubsection{Technical Background}

In a PNL draft report on tank waste robotics (TWR), several deployment scenarios have been identified for the conveyance system. These scenarios range from 1) a conveyance line internal to the long-reach arm and deployed through the same tank riser to 2) deployment of the manipulator and the conveyance system through separate risers in the tank, with remote attachment of the conveyance system to the end effector.

The conveyance system that will be part of the first-generation retrieval system will be required to transport wastes varying from supernate liquid and soft sludge to hard heel wastes. The conveyance must maintain a high degree of performance for the transport of all forms of waste.

A pneumatic conveyance system with a volumetric capacity of $3500 \mathrm{ft}^{3} / \mathrm{min}$ (blower displacement) operating at 15 to $18 \mathrm{in.} \mathrm{Hg}$ vacuum through a 10 -in.-diameter line will transport up to $6 \mathrm{ft}^{3} / \mathrm{min}$ of most material of approximately 100 to $150 \mathrm{lb} / \mathrm{ft}^{3}$ density for up to 250 lineal feet in any direction, including $60 \mathrm{ft}$ vertical lift. Pneumatic conveyance is most effective with particle sizes in the range of 0.01 to 0.25 in. Moisture generally has little effect except as noted below, and can be beneficial by reducing line wear. Some materials are problematic for pneumatic systems, but readily mitigated: a high fines content $(<125-$ mesh) and low moisture content ( $1 / 2 \%$ to $1 \%)$ may tend to cake inside the line. The hydraulic cutting process will produce a significant portion of fines, but the moisture content will be well above the problem range. 
Large ( $>1$-in. mean diameter) particles will reduce the system throughput, increase wear, and cause higher forces at bends. Particle size will be distributed as a function of waste properties, traverse speed, and secondary motion of the jet cutters, jet size, water pressure, and other factors. While there will be a certain fraction of larger particles, the mean size and distribution should be reasonably controllable.

Highly adhesive or cohesive materials will require an appropriate lubricant to prevent agglomeration into undesirable large bodies or accumulation and hold-up on the pipe wall. A small flow of fluid injected into the conveyance line at the inlet and other points is a proven method of dealing with this problem for some materials.

Flexible lines are commonly used in commercial applications. Endurance of flexible lines can be difficult to predict, and the combination of radiation, caustics, and abrasion compounds the uncertainty. A 10-in.-diameter flexible line will have a minimum bend radius of about $6 \mathrm{ft}$. Tighter bends require special hose to prevent kinking. Close bends can be made with rigid elbows. Bends in general cause an increase in head loss, tend to clog, incur higher reaction forces, and are to be avoided if possible and placed near the system inlet where velocity is lowest. Blind tees and special elbows based on blind tees with optimized internal configuration are preferred over sweeps or bends. Both use an accumulated pocket of transport material to protect the pipe fitting from abrasion (Bodner 1981, 1992).

Rigid straight conduits generally wear very well in dilute-phase transport of abrasives. A combination of lubricated flow and rigid or telescoping metal lines can give years of service life, with significant wear occurring at the bends and fittings.

Vertical conveyance is easier to sustain over long runs than is horizontal due to the problem of settling in horizontal lines. Settling will proceed until the constriction increases the flow velocity sufficiently to sustain transport, at which point an equilibrium will be maintained, but the constriction will reduce throughput and increase the power requirements. Maintaining operation in the dilutephase regime will prevent settling in an adequately powered system and give the best throughput. Lubrication, line flushing measures, line rotation, or agitation will mitigate any settling as a result of off-normal overloading.

\subsubsection{Conclusion}

The current baseline for the WD\&C demonstration program is pneumatic conveyance. Through proper design, pneumatic conveyance, which is commonly used in industry, has the ability to convey all types of waste. Based on findings from the literature and discussions with industrial consultants, pneumatic conveyance is a well founded approach for the first-generation system. It is important to note that in regimes of conveyance that are not well characterized, effective use of cutting fluid from the dislodging process as well as the potential use of additional lubricating liquid will be considered.

\subsection{Testing Focus Areas}

Based on these technology development needs, the WD\&C team developed eight activities required for completion of the concept demonstration phase of WD\&C work. The EM $30 / 50$ team deemed that these activities have a profound effect on the configuration and requirements for the first-generation long-reach manipulator. These have been categorized as concept bounding and definition and are the main drivers of the WD\&C testing program. The following is a description of these activities.

1. Define the mining strategy for each proposed dislodging and conveyance 
system. Deployment, control, maintenance, and maneuvering requirements may differ significantly between medium- and high-pressure dislodging applications as well as waterjet pump and air conveyance systems. Each of these parameters will drive first-generation long-reach arm requirements, particularly EM 30 efforts to define requirements for dynamics and level of control/automation.

2. Define, bound, and measure conveyance dynamic loads and dislodging dynamic loads. At very low fundamental frequencies $(<3 \mathrm{~Hz}$ ), the range of expected dynamic loads for each alternative will drive the arm design.

3. Define, bound, and measure the relationship between stand-off distance and depth of cut. Stand-off distance and depth of cut set the cross section that will be removed on successive waste removal passes. These data will determine arm requirements for accuracy, repeatability, level of control/automation, and dynamic stability. A shallow depth of cut requirement could prove impossible to meet with a long-reach arm design; the deployment system and dislodging/conveyance systems must have compatible requirements and behavior.

4. Define, bound, and measure the quality of the machined surface. The mining of the waste out of the tanks has a direct analogy to machining operations. The quality of the "machined" surface remaining after the first pass sets the requirements for waste removal strategy for successive passes and could determine waste removal rates.

5. Define, bound, and measure the effect of waterjets on tank wall and bottom structures. The potential tank liner damage is a concern that must be reconciled prior to the first-generation arm construction.

6. Determination of the sensitivity of the candidate waste dislodging and conveyance processes to waste properties is viewed as critical to the success of dislodging and conveyance system design. Granularity, tensile strength, and porosity are strong candidate physical properties that are drivers to both dislodging and conveyance system behaviors.

7. Define, bound, and measure the ability of the waste-dislodging concepts to deal "blindly" with changes in topography, without incumbent changes in process control parameters. This will measure the robustness of the wastedislodging process and, ideally, will lead to designs with minimal real-time contour monitoring requirements, thus reducing cost and risk and simplifying the arm design.

8. Document the bounding dimensions, capacities, requirements, and static and dynamic loads for normal and expected off-normal events. Communication of the assumptions and requirements to the end users of the technology is of key importance to the successful design, construction, and implementation of the first-generation system.

Collectively, the items discussed above are the eight focus areas on which WD\&C testing efforts have been and will be focused in FY94 and continuing on into FY95 to support the first-generation system. WD\&C has focused efforts on testing the recommended technologies to establish component performance parametric correlations and identify stable operating regimes such that risk and cost of the firstgeneration system can be minimized. 


\subsection{References}

Bamberger, J. A., J. M. Bates, J. K. Keska, M. R. Elmore, and N. J. Lombardo. 1993. Strategy Plan: Strategy to Develop and Test a Multi-Function Scarifier End Effector with an Integral Conveyance System for Waste Tank Remediation. PNL-8477, Pacific Northwest Laboratory, Richland, Washington.

Barnes, G. A., T. Rl. Benegas, R. R. Cruz, J. M. Henderson, E. L. Macke, J.D. Ludowise, S.W. Shaw, and K. G. Squires. 1991. Engineering Study for Partial Retrieval of Tank 241-C-106. WHC-SD-W139-ES-002, Revision 0 , Westinghouse Hanford Company, Richland, Washington.

Bodner, S. S. 1981. Effects of Bend Configuration on Dilute-Phase Pneumatic Transport. Exxon Nuclear Idaho Co., Inc. (for DOE).

Bodner, S. S. (Ed.) 1992. Best of Pneumatic Conveying. CSC Publishing, Minneapolis, Minnesota.

Ecology, EPA, DOE. 1989. Hanford Federal Facility Agreement and Consent Order. Washington State Department of Ecology, U.S. Environmental Protection Agency, and the U.S. Department of Energy, Olympia, Washington.

Gibbons, P. W., J. C. Sabin, M. C. Prather, and S. A. Krieg. 1993. Review of Prior SST Waste Retrieval Process Studies. WHC-SDWM-ES-252, Revision 0, Westinghouse Hanford Company, Richland, Washington.

Holden, R. L. C., and D. O. Monserud. 1993. AWJ for In-Tank Hardware Removal Final Report. Prepared by Quest Integrated, Inc. for Sandia National Laboratories.

Jaquish, W. R. 1993. Underground Storage Tank Waste Retrieval Technology Demonstra- tion Test Report. WHC-SD-TD-TRP-001, Westinghouse Hanford Company, Richland, Washington.

Krieg, S. A., W. W. Jenkins, K. J. Leist, K. G., Squires, and J. F. Thompson. 1990. Single Shell Tank Waste Retrieval Study. WHC-EP-0352, Revision 0, Westinghouse Hanford Company, Richland, Washington.

Leist, K. J. 1990. Air/Waterjet Scarifier Interim Test Report. WHC-SD-ER-TRP-004, Rev 0, Westinghouse Hanford Company, Richland, Washington.

Pezzimenti, D. M., P. M. Vlad, and B. Landau. 1989. The Use of the Deep Kerfer for Thick, Steel-Reinforced Concrete Cutting. DOE/NE/44139-58. West Valley Nuclear Services Co., Inc., West Valley, New York.

Powell, M. R. 1994. USTID Waste Dislodging and Conveyance FY93 Technology Development Summary Report. PNL-9787, Pacific Northwest Laboratory, Richland, Washington.

Quest Integrated, Inc. 1990. Water Jet and Airjet Scarifier Testing for Removal and Decontamination of Radioactive and Hazardous Waste. TR-511/11-90, Kent, Washington.

Squires, K. 1990a. Feature Test of the Pneumatic Needle Scaler. WHC-SD-ER-TRP-002. Westinghouse Hanford Company, Richland, Washington.

Squires, K. 1990b. Feature Test of the Sine Pump. WHC-SD-TRP-003, Westinghouse Hanford Company, Richland, Washington.

Thompson, J. F. 1990. Feature Test Of Air Conveyance System. WHC-SD-ER-TRP-001, Rev 0, Westinghouse Hanford Company, Richland, Washington. 
Thompson, J. F. 1993. Single Shell Tank

Soft Waste Dislodging and Conveyance Systems Development Test - Final Report. WHC-

SD-WM-TRP-171, Revision 0, Westinghouse

Hanford Company, Richland, Washington. 


\section{Distribution}

No. of

Copies

OFFSITE

2 DOE/Office of Scientific and Technical Information

Sherry Gibson

DOE HQ

12800 Middlebrook Rd.

Suite 400

Germantown, MD 20874

B. Burks

Oak Ridge National Laboratory

Oak Ridge, TN 37831-6304

C. Christensen

Idaho National Engrg Laboratory

PO Box 1625

Idaho Falls, ID 83415-3710

M. Christensen

Idaho National Engrg Laboratory

PO Box 1625

Idaho Falls, ID 83415-3710

DA Summers

Univ. of Missouri-Rolla

High Pressure Waterjet Lab

Rolla, MO 65401
No. of

Copies

ONSITE

2 DOE Richland Operations Office

DA Brown, K8-50

DE Trader, K8-50

6 Westinghouse Hanford Company

RC Eschenbaum, R3-50

PW Gibbons, S4-58

LB McDaniel, S6-12

OD Mullen, L5-08

EJ Shen, S4-58

JA Yount, L5-08

15 Pacific Northwest Laboratory

JA Bamberger, K7-15

WF Bonner, P7-41

DM Boyd, K5-10

GR Golcar, P7-19

BK Hatchell, K5-26

MJ Quadrell, K1-73

MW Rinker, K5-26 (2)

PA Scott, P7-43

Publishing Coordination

Technical Report Files (5)

Distr.1 